\title{
Sistem Pakar Diagnosa Penyakit Gigi Dan Mulut Menggunakan Metode Case-Based Reasoning
}

\author{
Chairun Nas \\ STMIK Catur Insan Cendikia \\ Jl. Kesambi No.202, Cirebon \\ e-mail: chairun.nas@cic.ac.id
}

\begin{abstract}
Abstrak
Penyakit gigi dan mulut menduduki peringkat pertama dari daftar 10 penyakit paling dikeluhkan oleh masyarakat. Hal ini disebabkan oleh kurangnya kesadaran masyarakat dalam menjaga kesehatan gigi dan mulut serta buruknya pengetahuan masyarakat akan dampak penyakit gigi dan mulut. Tujuan dari penelitian ini membantu dalam mendiagnosa penyakit gigi dan mulut yang dialami oleh pasien dengan menggunakan sistem pakar. Sistem pakar mengelola setiap gejala penyakit yang dirasakan oleh pasien dan melakukan pengujian menggunakan metode Case-Based Reasoning. Hasil dari pengujian metode Case-Based Reasoning dihasilkan sebuah diagnosa penyakit gigi dan mulut dengan tingkat kemiripan pada suatu penyakit sebesar 69,23\%. Maka metode ini dapat digunakan untuk mendiagnosa penyakit gigi dan mulut yang dialami oleh pasien, sehingga membantu dokter spesialis mengambil keputusan dalam penanganan penyakit.
\end{abstract}

Kata kunci: Sistem Pakar, Diagnoosa, Gigi Dan Mulut, Case-Based Reasoning

\begin{abstract}
Oral and dental disease was ranked first in the list of the 10 most complained of by the community. This is caused by a lack of public awareness in maintaining dental and oral health and poor public knowledge of the effects of dental and oral diseases. The purpose of this study helps in diagnosing dental and oral diseases experienced by patients using an expert system. The expert system manages every symptom of the disease felt by the patient and performs testing using the Case-Based Reasoning method. The results of testing the Case-Based Reasoning method produced a diagnosis of dental and oral diseases with a similarity in disease to 69.23\%. So this method can be used to diagnose dental and oral diseases experienced by patients, thus helping specialist doctors make decisions in handling diseases..
\end{abstract}

Keywords: Expert Systems, Diagnosis, Teeth and Mouth, Case-Based Reasoning

\section{PENDAHULUAN}

Seiring perkembangan zaman, kesadaran masyarakat indonesia akan kesehatan saat ini mulai berkurang. Hal ini disebabkan oleh banyaknya kegiatan atau aktifitas yang dilakukan sehingga masyarakat mulai mengabaikan kesehatan. Sering kali masyarakat tidak memperhatikan kesehatan gigi dan mulut setelah menyantap makanan sehingga menimbulkan penyakit gigi dan mulut. Berdasarkan penelitian, penyakit gigi dan mulut pada manusia menduduki urutan pertama dari daftar 10 besar penyakit yang paling banyak dikeluhkan masyarakat indonesia yang disebabkan persepsi dan perilaku masyarakat terhadap kesehatan gigi dan mulut masih buruk [1].

Diagnosa penyakit gigi dan mulut dilakukan oleh dokter spesialis gigi dan mulut berdasarkan gejala yang diterima dan bentuk kerusakan gigi atau mulut yang terlihat [2]. Namun seringkali masyarakat mengatasi gangguan kesehatan gigi dan mulut berdasarkan pengetahuan sendiri seperti menggunakan obat pereda nyeri [3]. Hal ini diakibatkan minimnya perilaku masyarakat untuk mengkonsultasikan penyakit yang dialami. Selanjutnya keterbatasan dokter spesialis dalam hal waktu dan banyaknya aktifitas juga menjadi faktor kekurangan dalam memberikan konsultasi pada masyarakat. Untuk mengatasi masalah tersebut, dibutuhkan suatu sistem pakar yang mampu mendiagnosa penyakit gigi dan mulut berdasarkan data klinis pasien. 
Sistem pakar secara umum mengadopsi pengetahuan manusia kedalam komputer agar komputer dapat menyelesaikan masalah secara sistematis seperti halnya manusia menyelesaikan masalah [4]. Didalam sistem pakar, terdapat teknik atau metode penalaran yang digunakan untuk menghasilkan sebuah penyelesaian. Salah satu teknik atau metode dalam sistem pakar adalah metode Case-Based Reasoning yang dapat memproses permasalahan yang diajukan dengan menggunakan solusi pada kasus sebelumnya yang memiliki persamaan kasus [5].

Penggunaan sistem pakar menggunakan metode Case-Based Reasoning sebelumnya telah dilakukan pada pendiagnosaan penyakit paru-paru. Pada penelitian ini dilakukan pengujian pada satu kasus baru dengan 8 kasus yang telah ada sebelumnya untuk di uji nilai kedekatannya. Dari hasil pengujian ini ditemukan kasus ke 5 yang memiliki tingkat kesamaan sebesar 0,93 atau 93\% dengan kasus baru yang dimasukkan. Sehingga metode ini dapat digunakan untuk melakukan diagnosa dengan membandingkan suatu kasus baru dengan kasus lama [6].

Sistem pakar untuk mendiagnosa penyakit gigi sebelumnya juga telah dilakukan dengan menggunakan metode Forward Chaining. Pada penelitian ini dilakukan pengujian terhadap 2 jenis penyakit gigi dan 14 gejala penyakitnya. Metode Forward Chaining melakukan pengujian diagosa terhadap penyakit gigi dengan mengikuti rule yang telah dibuat. Dari hasil pengujian didapatkan suatu jenis penyakit dimana melakukan 5 kali iterasi proses rule [3]. Kekurangan dari penggunaan metode ini adalah ketergantungan terhadap rule, apabila rule tidak terpenuhi, maka hasil diagnosa tidak ditemukan.

Dari penelitian yang telah dibahas sebelumnya, maka metode Case-Based Reasoning cocok digunakan dalam perancangan aplikasi sistem pakar untuk menentukan tingkat kemiripan suatu kasus.

\section{STUDI LITERATUR}

\subsection{Sistem Pakar}

Sistem pakar adalah sebuah sistem yang mengajarkan sebuah komputer agar komputer dapat menyelesaikan masalah seperti layanknya manusia yang ahli dibidangnya[7]. Sistem pakar dibangun agar dapat membantu orang awam dalam menyelesaikan permasalahan yang biasanya hanya dapat diselesaikan oleh seorang ahli atau pakar. Sistem pakar dikategorikan kedalam perangkat lunak tingkat tinggi, dimana didalam sistem tersebut ditanam logika agar dapat menduplikasi fungsi dari seorang ahli yang khusus dibidangnya [8]. Dengan adanya sistem pakar, maka keluaran yang akan dihasilkan lebih efektif, terorganisir dan tepat dibandingkan dengan keluaran yang dihasilkan oleh manusia [3].

Untuk pembangunan sistem pakar dibutuhkan komponen-komponen utama seperti Antarmuka Pengguna (User Interface), Basis Pengetahuan (Knowledge Base), Mekanisme Inferensi (Inference Machine) dan Memori Kerja (Working Memory) [1]. Komponen-komponen tersebut saling berintegrasi dalam membangun sistem pakar yang lebih efektif dan untuk menghasilkan keluaran yang tepat. Komponen knowledge base dalam sistem pakar bersifat khusus untuk satu domain masalah saja atau satu bidang masalah seperti bidang kedokteran, keuangan dan lain-lain [5].

Aplikasi Sistem Pakar disusun oleh dua bagian utama, yaitu lingkungan pengembang (Development Environment) yang berguna untuk memasukkan pengetahuan pakar kedalam lingkungan sistem pakar, sedangkan lingkungan konsultasi (Consultation Environment) berguna untuk memperoleh pengetahuan dari pakar [9].

\subsection{Case-Based Reasoning}

Case-Based Reasoning termasuk bagian dari representasi pengetehuan dimanamerupakan sebuah metode dalam sistem pakar yang berbasis pengetahuan. Case-Based Reasoning adalah satu penyelesaian masalah, dimana masalah tersebut diselesaikan dengan melihat pola atau keadaan yang telah terjadi sebelumnya [7]. Kapabilitas metode Case-Based Reasoning dibidang medis mencakup diagnosis, prognosis, terapi dan tindak lanjut pada pasien [4]. Maka dapat digambarkan secara sederhana bahwasanya metode Case-Based Reasoning dalam mendiagnosa melakukan pembandingan dengan kasus lama terhadap kasus baru.

Pada sebuah metode, terdapat tahapan yang dilakukan untuk mendapatkan hasil akhir. Secara umum proses metode Case-Based Reasoning terdiri dari 4 langkah pada Gambar 1, yaitu [6]:

1. Retrieve, merupakan proses pengenalan masalah dan pencarian persamaan masalah pada database. 
2. Reuse, merupakan proses menggunakan kembali informasi atau pengetahuan yang telah tersimpan pada database untuk memecahkan masalah.

3. Revise, merupakan proses untuk memperbaiki solusi yang diusulkan.

4. Retain, merupakan proses menyimpan pengetahuan yang nantinya akan digunakan untuk memecahkan masalah kedalam basis kasus yang ada.

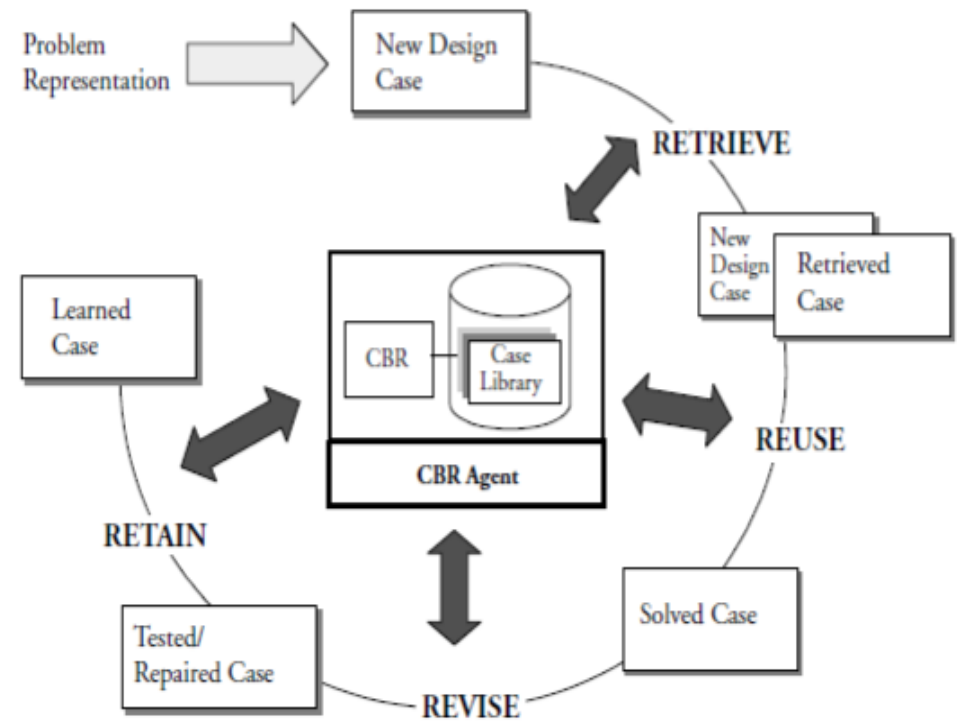

Gambar 1. Tahapan Case-Based Reasoning

Saat proses temu kembali kasus yang telah ada, akan dilakukan perhitungan tingkat kemiripan struktur antara kasus baru dengan objek yang ada pada kasus-kasus yang telah tersimpan sebelumnya. Fungsi kemiripan (Similarity) adalah langkah yang digunakan untuk mengenali kesamaan atau kemiripan antara kasus-kasus yang tersimpan dalam basis kasus dengan kasus yang baru [4]. Rumus dalam mencari nilai kemiripan yaitu :

$$
\text { Similarity }=\frac{s 1 * w 1+s 2 * w 2+. . s n * w n}{w 1+w 2+\ldots w n}
$$

Keterangan :

$\mathrm{S}$ = similarity jika terdapat kemiripan kasus maka akan bernilai 1, sedangkan tidak mirip, bernilai 0 .

$\mathrm{W}=$ weight (bobot yang diberikan).

\subsection{Penyakit Gigi Dan Mulut}

Penyakit adalah suatu proses penghancuran secara partikular dalam suatu organ atau organisme yang menyebabkan keadaan tidak nyaman yang dialami oleh tubuh dan pikiran [2]. Gigi tertanam didalam tulang rahang bawah dan atas serta tersusun dalam dua lengkungan rahang atas dan lengkungan rahang bawah, sehingga kedudukan gigi bawah agak melampaui gigi atas [1]. Gigi dan mulut menjadi tempat masuknya makanan yang kita makan, maka mulut dan gigi rentan mengalami sakit disebabkan bakteri apabila tidak menjaga kesehatan gigi dan mulut.

Maka penyakit gigi dan mulut dapat diartikan proses penghancuran secara partikular yang terjadi pada gigi dan mulut [2]. Penyakit gigi dan mulut dapat diartikan juga keadaan tidak normal yang terjadi pada gigi dan mulut-mulut yang disebabkan oleh gejala-gejala tertentu. Gejala umum yang sering terjadi pada penyakit gigi dan mulut dapat dilihat pada kondisi gigi dan mulut tersebut.

\section{METODOLOGI PENELITIAN}

Dalam penelitian ini, dapat diuraikan tahapan proses dalam pendiagnosaan penyakit gigi dan mulut menggunakan metode Case-Based Reasoning pada Gambar 2. 


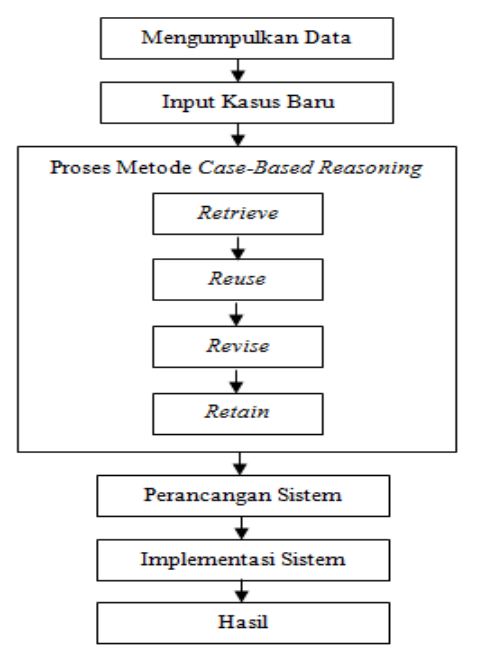

Gambar 2. Tahapan Proses Penelitian

\section{1 Pengumpulan Data}

Pada penelitian ini dilakukan pengumpulan berupa data jenis penyakit dan data gejala-gejala yang berhubungan dengan penyakit gigi dan mulut. Data diperoleh melalui wawancara dengan dokter spesialis gigi dan mulut. Adapun jenis penyakit yang diperoleh dapat dilihat pada Tabel 1 berikut:

Tabel 1. Data Penyakit Gigi Dan Mulut

\begin{tabular}{cl}
\hline Kode Penyakit & \multicolumn{1}{c}{ Nama Penyakit } \\
\hline P01 & Gingivitis Ulseratif Nekrosisakut \\
P02 & Trench Mouth \\
P03 & Candidiasis Oral \\
P04 & Abses Periodental \\
P05 & Glosistis \\
P06 & Abses Periapikal \\
P07 & Herpes Labialis \\
P08 & Stomatitis Angularis \\
P09 & Gingivostomatitis \\
\hline
\end{tabular}

Dari data yang diperoleh, didapatkan 9 jenis penyakit gigi dan mulut. Selanjutnya gejala-gejala dari penyakit serta hubungan antara gejala dan penyakit yang dapat dilihat pada Tabel 2 berikut:

Tabel 2. Data Gejala Penyakit Gigi Dan Mulut

\begin{tabular}{|c|c|c|c|c|c|c|c|c|c|c|c|}
\hline \multirow{2}{*}{ Kode } & \multirow{2}{*}{ Nama Gejala } & \multicolumn{9}{|c|}{ Penyakit } & \multirow[t]{2}{*}{ Bobot } \\
\hline & & $\mathrm{P} 01$ & $\mathrm{P} 02$ & $\mathrm{P} 03$ & $\mathrm{P} 04$ & $\mathrm{P} 05$ & P06 & $\mathrm{P} 07$ & $\mathrm{P} 08$ & $\mathrm{P} 09$ & \\
\hline G01 & Bau mulut & $*$ & $*$ & & & & & & & $*$ & 1 \\
\hline G02 & Gusi bengkak, merah dan berdarah & $*$ & & & & & & & & & 3 \\
\hline G04 & Kelelahan & & $*$ & & & & & & & & 1 \\
\hline G05 & $\begin{array}{l}\text { Gingival berkaratin, gaung luka diantara gigi } \\
\text { dan gusi }\end{array}$ & $*$ & & & & & & & & & 3 \\
\hline G07 & Demam & $*$ & * & & & & $*$ & & & $*$ & 3 \\
\hline G08 & Gusi mudah berdarah & & $*$ & & & & & & & & 3 \\
\hline G09 & $\begin{array}{l}\text { Kelenjer getah bening dibawah rahang sering } \\
\text { kali membengkak }\end{array}$ & & $*$ & & & & & & & & 3 \\
\hline G10 & $\begin{array}{l}\text { Mengunyah dan menelan makanan } \\
\text { menyebabkan rasa nyeri }\end{array}$ & & $*$ & & & & $*$ & & & & 5 \\
\hline G14 & Pecah-pecah dan kemerahan pada sudut mulut & & & $*$ & & & & & & & 3 \\
\hline G15 & Peradangan pada lidah & & & & & $*$ & & & & & 5 \\
\hline G16 & Pembekakan kelenjer getah bening leher & & & & & & $*$ & & & & 5 \\
\hline G17 & Permungkaan lidah yang halus & & & & & $*$ & & & & & 1 \\
\hline
\end{tabular}




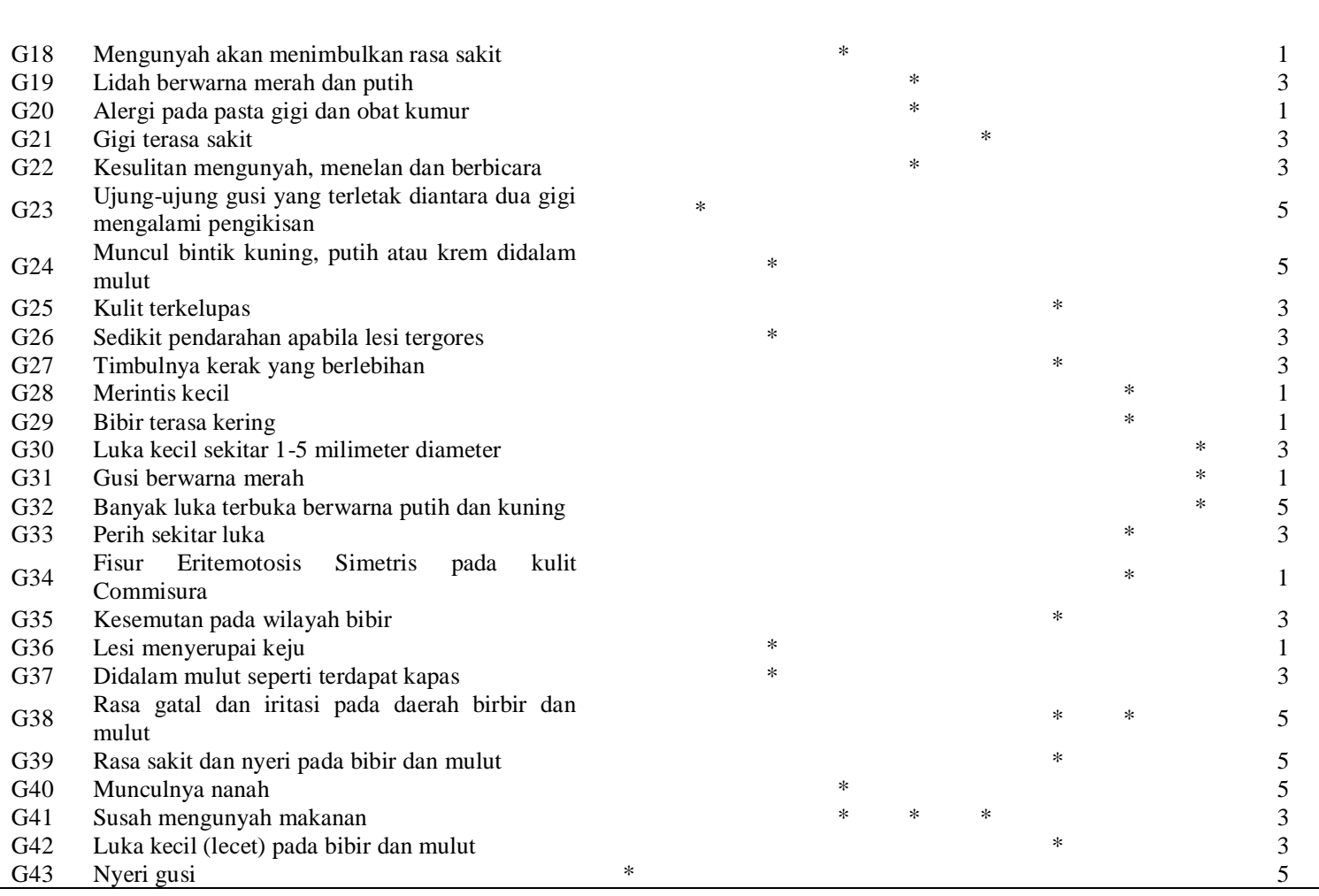

Setiap penyakit memiliki gejalanya masing-masing dan setiap gejala juga memiliki bobot nilainya. bobot gejala dikelompokkan ke dalam 3 jenis :

a. Gejala dengan bobot bernilai 1 digolongkan kedalam gejala ringan.

b. Gejala dengan bobot bernilai 3 digolongkan kedalam gejala sedang.

c. Gejala dengan bobot bernilai 5 digolongkan kedalam gejala berat.

Hubungan antara penyakit dan gejala ini dapat dijadikan sebagai basis kasus lama dalam proses metode Case-Based Reasoning, dimana basis kasus tersebut akan dibandingkan dengan kasus baru.

\subsection{Input Kasus Baru}

Dalam penelitian ini dilakukan pengujian dengan menggunakan kasus baru. Kasus baru diperoleh melalui gejala yang dirasakan oleh pasien saat ini, sehingga dapat ditemukan jenis penyakit gigi dan mulut yang diderita. Kasus baru yang diperoleh dapat dilihat pada Tabel 3 berikut:

Tabel 3. Data Kasus Baru / Gejala Yang Dirasakan Pasien

\begin{tabular}{ccl}
\hline No & Kode Gejala & \\
\hline 1. & G23 & Ujung-ujung gusi yang terletak diantara dua gigi mengalami pengikisan \\
2. & G40 & Munculnya nanah \\
3. & G43 & Nyeri gusi \\
4. & G02 & Gusi bengkak, merah dan berdarah \\
5. & G08 & Gusi mudah berdarah \\
6. & G21 & Gigi terasa sakit \\
7. & G41 & Susah mengunyah makanan \\
8. & G01 & Bau mulut \\
9. & G11 & Kehilangan selera makanan \\
10. & G18 & Mengunyah akan menimbulkan rasa sakit \\
11. & G31 & Gusi berwarna merah \\
\hline
\end{tabular}

\subsection{Proses Metode Case-Based Reasoning}

Setelah seluruh data yang dibutuhkan dikumpulkan, selanjutnya dapat dilakukan proses metode Case-Based Reasoning. Pada proses metode ini, ada 4 tahapan yang harus dilakukan yaitu, tahapan Retrieve, dimana pada tahapan ini dilakukan proses pengenalan masalah dan pencarian masalah pada database. Selanjutnya tahapan Reuse yang digunakan untuk menggunakan kembali pengetahuan yang 
telah tersimpan sebelumnya dimana diartikan sebagai proses pencarian nilai similarity. Tahapan selanjutnya yaitu Revise, dimana solusi yang dihasilkan akan dievaluasi kembali. Dan terakhir tahapan Retain yang merupakan tahapan proses penyimpanan pengetahuan yang dihasilkan ke dalam database.

\subsection{Perancangan Sistem}

sistem pakar dalam penelitian ini dirancang menggunakan UML (Unified Modelling Language) agar mempermudah memindahkan konsep sistem yang dirancang kedalam bentuk aplikasi. Perancangan sistem dirancangkan dalam 2 bentuk, yaitu Use Case Diagram yang menggambarkan hubungan antara aktor dengan sistem dan Class Diagram yang menggambarkan hubungan data-data yang ada dalam sistem. Adapun bentuk Use Case dan Class Diagram dapat dilihat pada Gambar 3 dan Gambar 4 berikut:

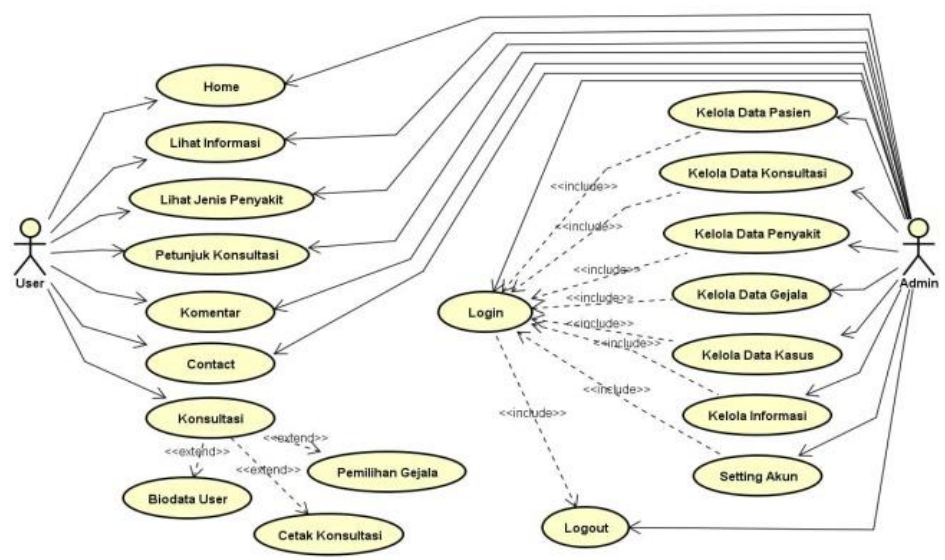

Gambar 3. Use Case Diagram

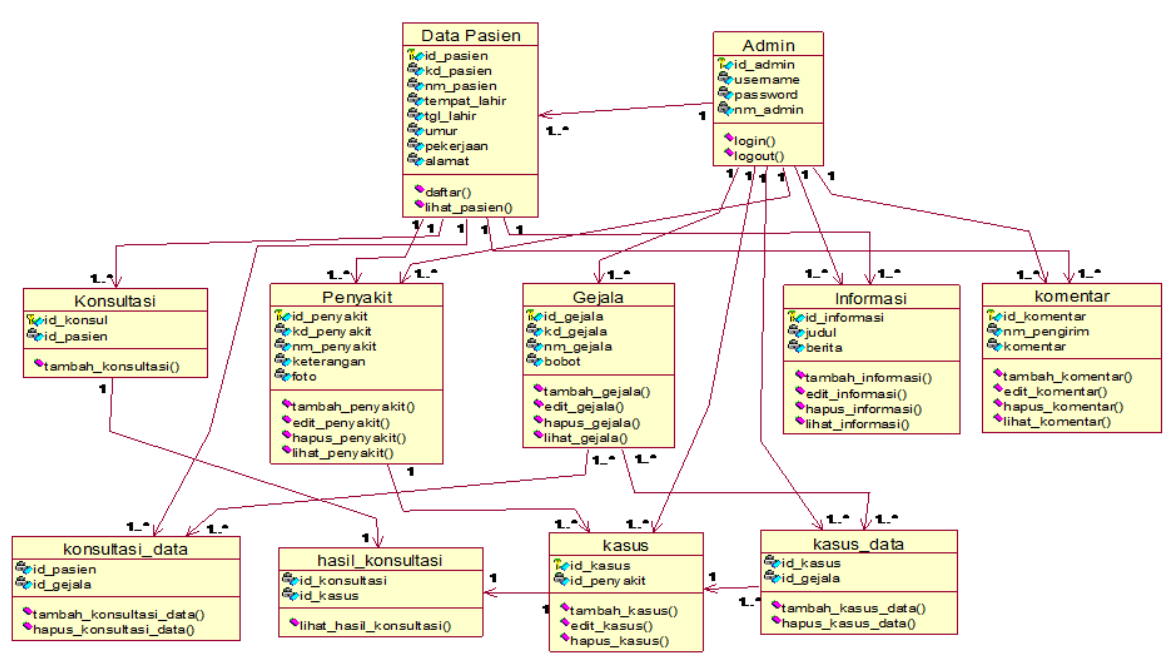

Gambar 4. Class Diagram

\subsection{Implementasi Sistem}

Sistem pakar dalam penelitian ini diimplementasikan ke dalam web yang dibangun menggunakan bahasa pemograman php dan MySql. Tujuan sistem pakar ini diimplementasikan kedalam bentuk aplikasi web agar sistem pakar ini dapat diakses oleh user dimanapun dan kapanpun menggunakan jaringan internet.

\section{ANALISA DAN HASIL}

Pada analisa sistem pakar ini, dilakukan proses berdasarkan tahapan dari metode Case-Based Reasoning, maka dilakukan analisa pada setiap tahapan sebagai berikut: 


\subsection{Tahapan Retrieve}

Sebagaimana telah dijelaskan sebelumnya, pada tahapan ini dilakukan proses pengenalan masalah dan pencarian masalah pada database. Pencarian masalah tersebut dilakukan untuk setiap masing-masing jenis penyakit yang dapat dijelaskan sebagai berikut:

a. Penyakit Gigi Dan Mulut Jenis Gingivitis Ulseratif Nekrosis Akut

Untuk pencarian masalah penyakit Gingvitis Ulseratif Nekrosis Akut pada kasus baru yang diperoleh, maka dapat dilihat hubungannya pada Gambar 5 berikut:

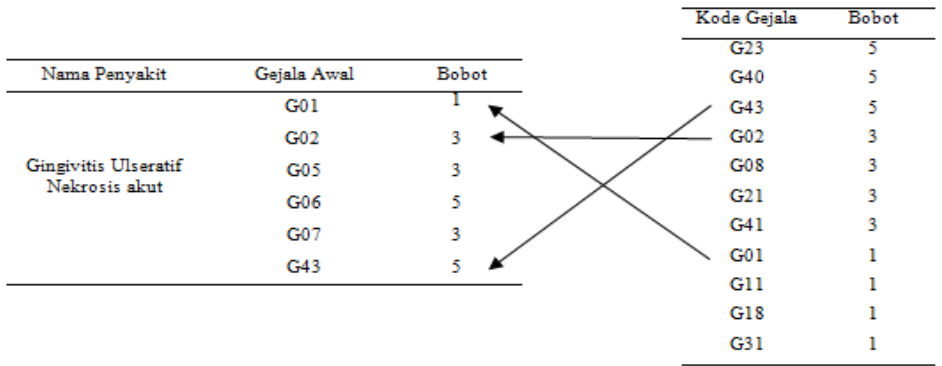

Gambar 5. Pencarian Kasus Baru Pada Jenis Penyakit Gingvitis Ulseratif Nekrosis Akut

b. Penyakit Gigi Dan Mulut Jenis Trench Mouth

Untuk pencarian masalah penyakit Trench Mouth pada kasus baru yang diperoleh, maka dapat dilihat hubungannya pada Gambar 6 berikut:

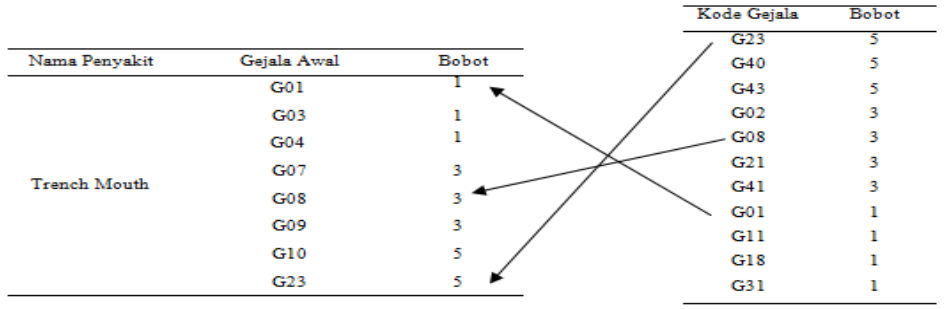

Gambar 6. Pencarian Kasus Baru Pada Jenis Penyakit Trench Mouth

c. Penyakit Gigi Dan Mulut Jenis Candidiasis Oral

Untuk pencarian masalah penyakit Candidiasis Oral pada kasus baru yang diperoleh, maka dilihat hubungannya pada Gambar 7 Berikut:

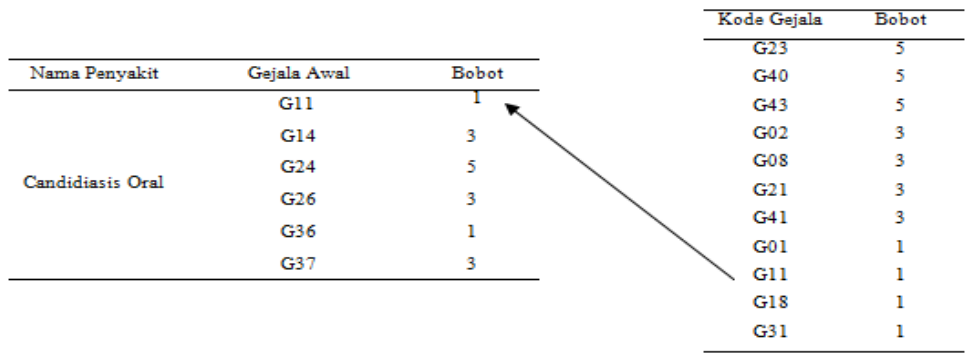

Gambar 7. Pencarian Kasus Baru Pada Jenis Penyakit Candidiasis Oral

d. Penyakit Gigi dan Mulut Jenis Abses Periodental

Untuk pencarian masalah penyakit Abses Periodental pada kasus baru yang diperoleh, maka dilihat hubungannya pada Gambar 8 berikut: 


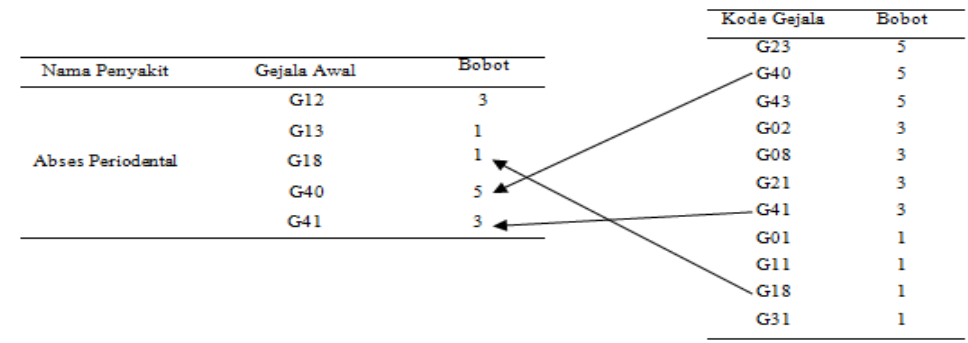

Gambar 8. Pencarian Kasus Baru Pada Jenis Penyakit Abses Periodental e. Penyakit Gigi dan Mulut Jenis Glositis

Untuk pencarian masalah penyakit Glositis pada kasus baru yang diperoleh, maka dilihat hubungannya pada Gambar 9 berikut:

\begin{tabular}{|c|c|c|c|c|}
\hline & & & Rode Gejala & \\
\hline & & & G23 & 5 \\
\hline Nama Penyakit & Gejala Awal & Bobot & $\mathrm{G} 40$ & 5 \\
\hline \multirow{7}{*}{ Glositis } & G15 & 5 & $\mathrm{G} 43$ & 5 \\
\hline & G17 & 1 & $\mathrm{G} 02$ & 3 \\
\hline & G19 & 3 & G08 & 3 \\
\hline & $\mathrm{G} 20$ & 1 & $\mathrm{G} 21$ & 3 \\
\hline & $\mathrm{G} 22$ & 3 & G4 1 & 3 \\
\hline & G41 & 3 & G01 & 1 \\
\hline & & & G11 & 1 \\
\hline & & & G18 & 1 \\
\hline & & & G31 & 1 \\
\hline
\end{tabular}

Gambar 9. Pencarian Kasus Baru Pada Jenis Penyakit Glositis

f. Penyakit Gigi dan Mulut Jenis Abses Periapikal

Untuk pencarian masalah penyakit Abses Periapikal pada kasus baru yang diperoleh, maka dilihat hubungannya pada Gambar 10 berikut:

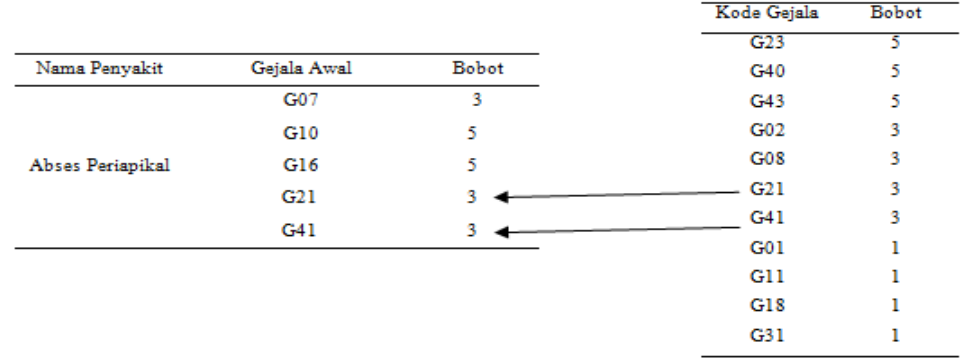

Gambar 10. Pencarian Kasus Baru Pada Jenis Penyakit Abses Periapikal

g. Penyakit Gigi dan Mulut Jenis Herpes Labialis

Untuk pencarian masalah penyakit Herpes Labialis pada kasus baru yang diperoleh, maka dilihat hubungannya pada Gambar 11 berikut:

\begin{tabular}{|c|c|c|c|c|}
\hline & & & \multicolumn{2}{|l|}{ Kode Gainl } \\
\hline & & & G23 & 5 \\
\hline Nama Penyakit & Gejala Awal & Bobot & $\mathrm{G} 40$ & 5 \\
\hline \multirow{9}{*}{ Herbes Labialis } & G11 & 1 & G43 & 5 \\
\hline & G13 & 1 & $\mathrm{G} 02$ & 3 \\
\hline & G25 & 3 & G08 & 3 \\
\hline & G27 & 3 & G21 & 3 \\
\hline & G35 & 3 & G41 & 3 \\
\hline & G38 & 5 & G01 & 1 \\
\hline & & & G1 1 & 1 \\
\hline & G39 & 5 & G18 & 1 \\
\hline & $\mathrm{G} 42$ & 3 & G31 & 1 \\
\hline
\end{tabular}

Gambar 11. Pencarian Kasus Baru Pada Jenis Penyakit Herpes Labialis

h. Penyakit Gigi dan Mulut Jenis Stomatitis Angularis 
Untuk pencarian masalah penyakit Stomatitis Angularis pada kasus baru yang diperoleh, maka dilihat hubungannya pada Gambar 12 berikut:

\begin{tabular}{ccc}
\hline Nama Penyakit & Gejala Awal & Bobot \\
\hline & G28 & 1 \\
Stomatitis & G29 & 1 \\
Angularis & G33 & 3 \\
& G34 & 1 \\
& G38 & 5 \\
\hline
\end{tabular}

\begin{tabular}{cc}
\hline Kode Gejala & Bobot \\
\hline G23 & 5 \\
G40 & 5 \\
G43 & 5 \\
G02 & 3 \\
G08 & 3 \\
G21 & 3 \\
G41 & 3 \\
G01 & 1 \\
G11 & 1 \\
G18 & 1 \\
G31 & 1 \\
\hline
\end{tabular}

Gambar 12. Pencarian Kasus Baru Pada Jenis Penyakit Stomatitis Angularis

i. Penyakit Gigi dan Mulut Jenis Gingivostomatitis

Untuk pencarian masalah penyakit Gingivostomatitis pada kasus baru yang diperoleh, maka dilihat hubungannya pada Gambar 13 berikut:

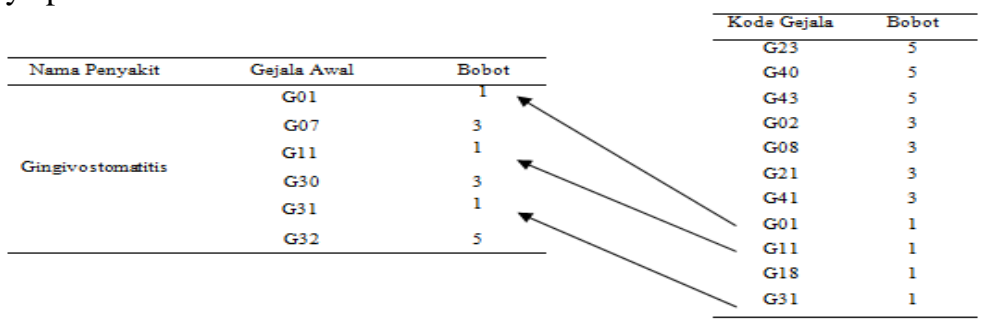

Gambar 12. Pencarian Kasus Baru Pada Jenis Penyakit Gingivostomatitis

\subsection{Tahapan Reuse}

Pada tahapan reuse, dilakukan perhitungan similarity untuk mencari tingkat kemiripan kasus lama dengan kasus baru. Adapun proses pencarian kemiripan ini dapat dijelaskan sebagai berikut:

a. Tingkat Kemiripan Pada Penyakit Ginggivitis Ulseratif Nekrosis Akut

Dari hubungan kasus lama dengan kasus baru yang dilakukan pada tahapan Retrieve, maka diperoleh 3 gejala yang sama, maka dari hubungan tersebut didapatkan similarity sebagai berikut:

$$
\begin{aligned}
\text { Similarity (1) } & =\frac{s 1 * w 1+s 2 * w 2+. . s n * w n}{w 1+w 2+\ldots w n} \\
& =\frac{1 * 1+1 * 3+0 * 3+0 * 5+0 * 3+1 * 5}{1+3+3+5+3+5} \\
& =\frac{9}{20}=0,45 \\
& =45 \%
\end{aligned}
$$

b. Tingkat Kemiripan Pada Penyakit Trench Mouth

Dari hubungan kasus lama dengan kasus baru yang dilakukan pada tahapan Retrieve, maka diperoleh 3 gejala yang sama, maka dari hubungan tersebut didapatkan similarity sebagai berikut:

$$
\begin{aligned}
\text { Similarity (2) } & =\frac{s 1 * w 1+s 2 * w 2+. . s n * w n}{w 1+w 2+\ldots w n} \\
& =\frac{1 * 1+0 * 1+0 * 1+0 * 3+1 * 3+0 * 3+0 * 5+1 * 5}{1+1+1+3+3+3+5+5} \\
& =\frac{9}{22}=0,40909 \\
& =40,9 \%
\end{aligned}
$$


c. Tingkat Kemiripan Pada Penyakit Candidiasis Oral

Dari hubungan kasus lama dengan kasus baru yang dilakukan pada tahapan Retrieve, maka diperoleh 1 gejala yang sama, maka dari hubungan tersebut didapatkan similarity sebagai berikut:

$$
\begin{aligned}
\text { Similarity (3) } & =\frac{s 1 * w 1+s 2 * w 2+. . s n * w n}{w 1+w 2+\ldots w n} \\
& =\frac{0 * 3+0 * 5+0 * 3+0 * 1+0 * 3+1 * 1}{3+5+3+1+3+1} \\
& =\frac{1}{16}=0,0625 \\
& =6,25 \%
\end{aligned}
$$

d. Tingkat Kemiripan Pada Penyakit Abses Periodental

Dari hubungan kasus lama dengan kasus baru yang dilakukan pada tahapan Retrieve, maka diperoleh 3 gejala yang sama, maka dari hubungan tersebut didapatkan similarity sebagai berikut:

$$
\begin{aligned}
\text { Similarity (4) } & =\frac{s 1 * w 1+s 2 * w 2+. . s n * w n}{w 1+w 2+\ldots w n} \\
& =\frac{0 * 3+0 * 1+1 * 1+1 * 5+1 * 3}{3+1+1+5+3} \\
& =\frac{9}{13}=0,6923 \\
& =69,23 \%
\end{aligned}
$$

e. Tingkat Kemiripan Pada Penyakit Glositis

Dari hubungan kasus lama dengan kasus baru yang dilakukan pada tahapan Retrieve, maka diperoleh 1 gejala yang sama, maka dari hubungan tersebut didapatkan similarity sebagai berikut:

$$
\begin{aligned}
\text { Similarity (5) } & =\frac{s 1 * w 1+s 2 * w 2+. . s n * w n}{w 1+w 2+\ldots w n} \\
& =\frac{0 * 5+0 * 1+0 * 3+0 * 1+0 * 3+1 * 3}{5+1+3+1+3+3} \\
& =\frac{3}{16}=0,1875 \\
& =18,75 \%
\end{aligned}
$$

f. Tingkat Kemiripan Pada Penyakit Abses Periapikal

Dari hubungan kasus lama dengan kasus baru yang dilakukan pada tahapan Retrieve, maka diperoleh 2 gejala yang sama, maka dari hubungan tersebut didapatkan similarity sebagai berikut:

$$
\begin{aligned}
\operatorname{Similarity}(6) & =\frac{s 1 * w 1+s 2 * w 2+. . s n * w n}{w 1+w 2+\ldots w n} \\
& =\frac{0 * 3+0 * 5+0 * 5+1 * 3+1 * 3}{3+5+5+3+3} \\
& =\frac{6}{19}=0,3157 \\
& =31,57 \%
\end{aligned}
$$


g. Tingkat Kemiripan Pada Penyakit Herpes Labialis

Dari hubungan kasus lama dengan kasus baru yang dilakukan pada tahapan Retrieve, maka diperoleh 1 gejala yang sama, maka dari hubungan tersebut didapatkan similarity sebagai berikut:

$$
\begin{aligned}
\text { Similarity }(7) & =\frac{s 1 * w 1+s 2 * w 2+. . s n * w n}{w 1+w 2+. . w n} \\
& =\frac{1 * 1+0 * 1+0 * 3+0 * 3+0 * 3+0 * 5+0 * 5+0 * 3}{1+1+3+3+3+5+5+3} \\
& =\frac{1}{24}=0,0416 \\
& =4,16 \%
\end{aligned}
$$

h. Tingkat Kemiripan Pada Penyakit Stomatitis Angularis

Dari hubungan kasus lama dengan kasus baru yang dilakukan pada tahapan Retrieve, maka diperoleh 0 gejala yang sama, maka dari hubungan tersebut didapatkan similarity sebagai berikut:

$$
\begin{aligned}
\text { Similarity }(8) & =\frac{s 1 * w 1+s 2 * w 2+. . s n * w n}{w 1+w 2+\ldots w n} \\
& =\frac{0 * 1+0 * 3+0 * 3+0 * 1+0 * 5}{1+3+3+1+5} \\
& =\frac{0}{13}=0 \\
& =0 \%
\end{aligned}
$$

i. Tingkat Kemiripan Pada Penyakit Gingivostomatitis

Dari hubungan kasus lama dengan kasus baru yang dilakukan pada tahapan Retrieve, maka diperoleh 3 gejala yang sama, maka dari hubungan tersebut didapatkan similarity sebagai berikut:

$$
\begin{aligned}
\operatorname{Similarity}(9) & =\frac{s 1 * w 1+s 2 * w 2+. . s n * w n}{w 1+w 2+\ldots w n} \\
& =\frac{1 * 1+0 * 3+1 * 1+0 * 3+1 * 1+0 * 5}{1+3+1+3+1+5} \\
& =\frac{3}{14}=0,2142 \\
& =21,42 \%
\end{aligned}
$$

\subsection{Tahapan Revise}

Pada tahapan ini dilakukan proses meninjau kembali hasil yang diperoleh dari proses similarity. Dari perhitungan similarity untuk setiap jenis penyakit gigi dan mulut, ditemukan jenis penyakit Abses Periodental sebagai nilai similarity tertinggi dengan nilai kemiripan sebesar 69,23\%. Sedangkan untuk jenis penyakit Stomatitis Angularis memiliki nilai similarity terendah dengan nilai kemiripan 0\%.

Maka dari hasil tersebut dapat dilakukan diagnosa, bahwa pasien mengalami penyakit Abses Periodental dengan nilai kemiripan sebesar $69,23 \%$ dan pasien tidak memiliki kemungkinan untuk terjangkit penyakit Stomatitis Angularis.

\subsection{Tahapan Retain}


Pada tahapan ini, kasus baru yang telah di uji dengan setiap jenis penyakit gigi dan mulut dapat dimasukkan kedalam database. Hal ini bertujuan apabila dilakukan proses pencarian kasus baru dan kasus lama, kasus ini dapat digunakan untuk dibandingkan pada kasus baru lainnya.

\subsection{Pengujian Sistem Pakar Penyakit Gigi Dan Mulut}

Pengujian sistem menggambarkan bagaimana sebuah sistem berjalan. Tahapan pengujian ini berisikan hasil eksekusi program dan penjelasan program yang telah dirancang. Adapun tampilan sistem yang telah dibangun dapat dilihat sebagai berikut:

a. Tampilan Halaman Utama

Tampilan Halaman Utama merupakan tampilan awal dari sistem. Pada Halaman Utama terdapat menu-menu yang dapat diakses dalam menjalankan program. Adapun tampilan Halaman Utama dapat dilihat pada Gambar 13 berikut:

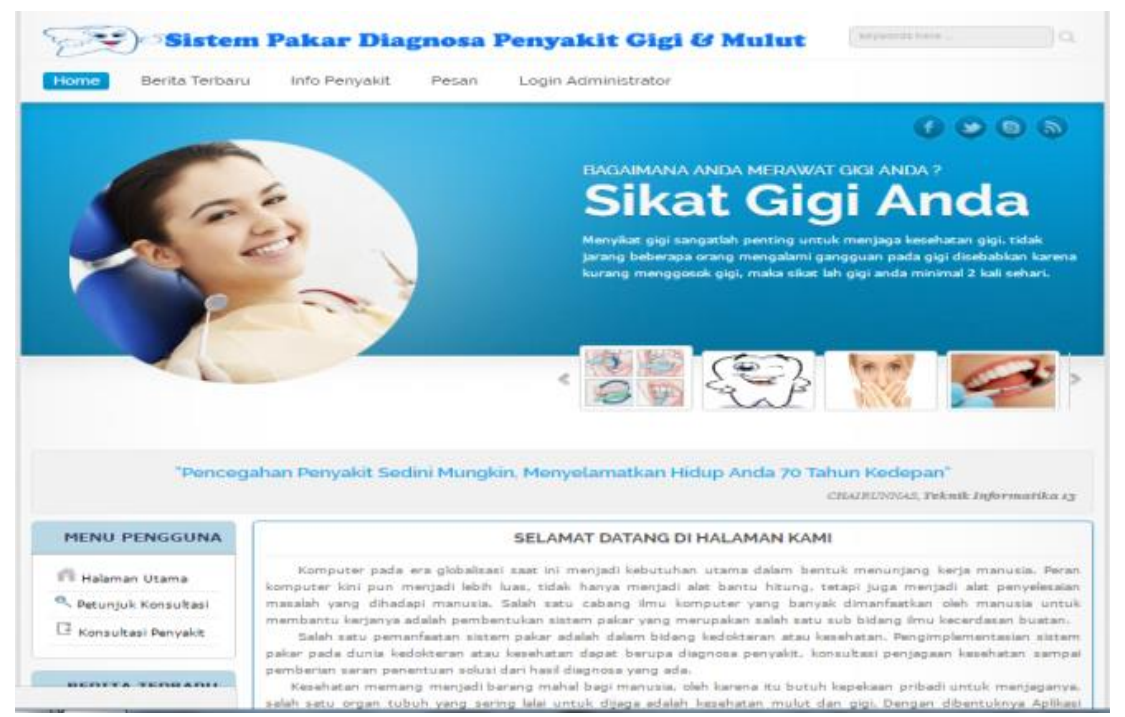

Gambar 13. Halaman Utama Sistem Pakar

b. Tampilan Form Hasil Diagnosa

Tampilan Form Hasil Diagnosa merupakan halaman yang menampilkan jenis penyakit yang dialami oleh pasien. Pada halaman ini juga dijelaskan keterangan tentang penyakit, penyebab penyakit dan pencegahannya. Adapun tampilan Form Hasil Diagnosa dapat dilihat pada Gambar 17 berikut:

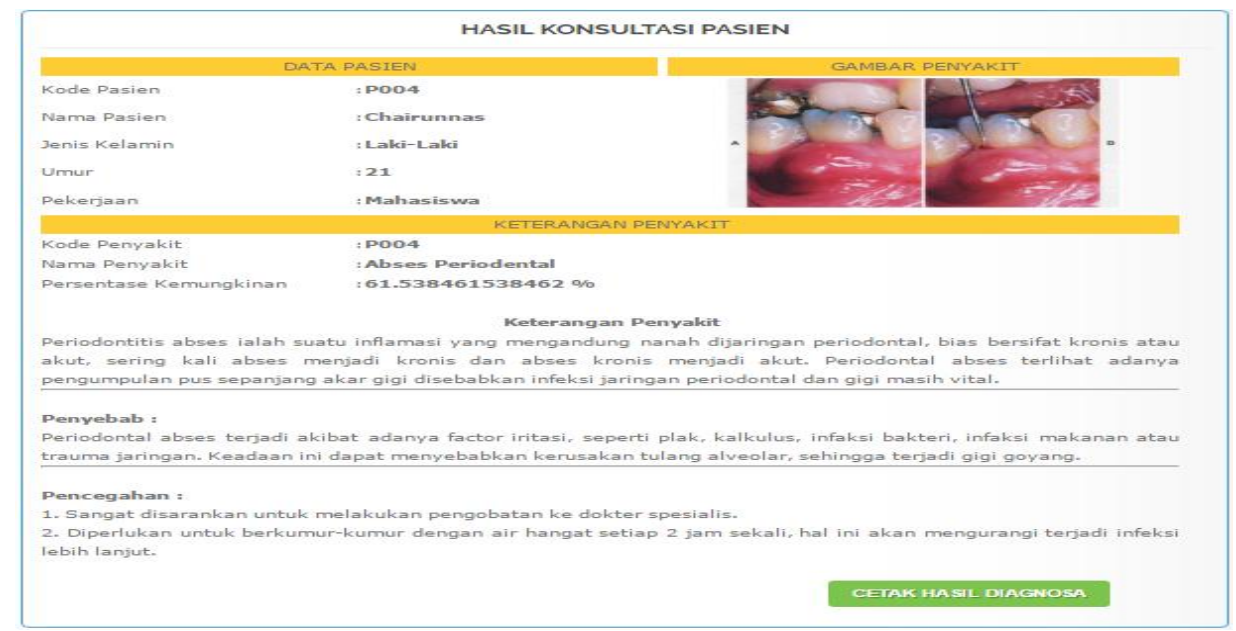

Gambar 17. Form Hasil Diagnosa Sistem Pakar 


\section{KESIMPULAN}

Berdasarkan pembahasan yang telah dijelaskan, maka dari penelitian ini didapatkan kesimpulan dan saran sebagai berikut:

\subsection{Simpulan}

Sistem pakar dengan menggunakan metode Case-Based Reasoning telah dapat melakukan analisa terhadap data gejala-gejala yang dirasakan oleh pasien dengan mencari kemiripan pada kasus lama. Dari hasil analisa tersebut, diperoleh nilai kemiripan tertinggi sebesar 69,23\% pada sebuah penyakit gigi dan mulut, sehingga pasien dapat di diagnosa mengalami penyakit gigi dan mulut. Maka dengan hasil diagnosa tersebut, dapat membantu dokter spesialis mengambil keputusan dalam melakukan tindakan selanjutnya.

\subsection{Saran}

Dalam penelitian selanjutnya, diharapkan adanya pengembangan metode Case-Based Reasoning menggunakan metode sistem pakar lainnya, sehingga didapatkan hasil yang lebih maksimal dan komplek. Sehingga dalam pendiagnosaan sebuah penyakit didapatkan hasil yang mendekati kebenaran.

Provide a statement that what is expected, as stated in the "Introduction" chapter can ultimately result in "Results and Discussion" chapter, so there is compatibility. Moreover, it can also be added the prospect of the development of research results and application prospects of further studies into the next (based on result and discussion).

\section{DAFTAR PUSTAKA}

[1] Nurzaman, Destiani D, Dhamiri D. Pembangunan Aplikasi Sistem Pakar untuk Diagnosis Penyakit Gigi Dan Mulut Pada Manusia. Jurnal Algoritma. 2012; 9(12): 1-8. ISSN 2302-7339.

[2] Makarios A, Prasetiyowati M. Rancang Bangun Sistem Pakar untuk Diagnosis Penyakit Mulut Dan Gigi dengan Metode Fuzzy Logic. ULTIMATICS. 2012; 4(2): 1-6. ISSN 2085-4552.

[3] Silvia, Leonita C, Virginia, Candra Y, Sevani N. Aplikasi Diagnosis Karies Pada Gigi Manusia Berbasis Web. ULTIMATICS. 2015; 7(1): 43-49. ISSN 2085-4552.

[4] Fatmayati F. Rancangan Sistem Penalaran Berbasis Kasus Untuk Mendiagnosa Penyakit Gigi dan Mulut. Seminar Nasional Teknologi Informasi Dan Multimedia. 2015; 55-60. ISSN 2302-3805.

[5] Retnowati R, Pujiyanta A. Implementasi Case Base Reasoning Pada Sistem Pakar Dalam Menentukan Jenis Gangguan Kejiwaan. Jurnal Sarja Teknik Informatika. 2013; 1(1): 69-78. ISSN 2338-5197.

[6] Kusuma D, Chairani. Rancang Bangun Sistem akar Pendiagnosa Penyakit Paru-Paru Menggunakan Metode Case Based Reasoning. Jurnal Infotel. 2014; 6(2): 57-62.

[7] Irfandi M, Romadhony A, Saadah S. Implementasi Sistem Pakar Diagnosa Penyakit Gigi dan Mulut Menggunakan Metode Hybrid Case-Based dan Rule-Based Reasoning. Indonesia Symposium On Computing. 2015; 219-225. ISSN 2460-3295

[8] Setiabudi W, Sugiharti E, Arini F. Expert System Diagnosis Dental Disease Using Certanty Factor Method. Scientific Journal of Informatics. 2017; 4(1): 43-50. ISSN 2407-7658

[9] Nas C. Sistem Pakar Diagnosa Penyakit Tiroid Menggunakan Metode Dempster Shafer. Jurnal Teknologi Dan Open Source. 2019; 2(1): 1-14. ISSN 2655-7592 